${ }^{\circledR}$ Entomologica Fennica. 8 July 1997

\title{
Willow tree shoot module length and the attack and survival pattern of a shoot-galling sawfly, Euura atra (Hymenoptera: Tenthredinidae)
}

\section{Peter W. Price, Heikki Roininen \& Jorma Tahvanainen}

Price, P. W., Roininen, H. \& Tahvanainen, J. 1997: Willow tree shoot module length and the attack and survival pattern of a shoot-galling sawfly, Euura atra (Hymenoptera: Tenthredinidae). — Entomol. Fennica 8: 113-119.

A small population of the shoot-galling sawfly, Euura atra (Jurine), attacking the willow, Salix alba L. (Salicaceae) in Joensuu, Finland, showed strong preference-performance linkage between female ovipositional choices and survival of progeny. Although shoot lengths on trees were most common in the classes $200-400 \mathrm{~mm}$, the probability of attack increased with shoot length until rare long shoots over $400 \mathrm{~mm}$ had a $50-80 \%$ probability of attack. The regression of attack probability on shoot length class accounted for $91 \%$ of the variance in attack. Attack was significantly greater on longer shoot length classes than that predicted by random attack based on total shoot length available per class, or total number of shoots per class. As shoot length increased the mean number of galls per shoot increased from 0 to 3 per shoot, and establishment and survival of progeny increased from 0 to over $60 \%$. Shoot length class accounted for $70 \%$ and $50 \%$ of the variance in larval establishment and ultimate survival respectively, while attack by carnivores showed no pattern and had no explanatory power. The results are consistent with those from studies on seven other Euura species showing attack on rapidly growing plants, an ovipositional preference for longer shoots, higher survival on longer shoots, and no detectable effects of carnivores on pattern generation. The study aids in the development of a strong comparative ecology of galling sawflies and the eventual development of empirically based factual theory on their population dynamics.

Peter W. Price, Department of Biological Sciences, Northern Arizona University, Flagstaff, Arizona 86011-5640, USA

Heikki Roininen \& Jorma Tahvanainen, Department of Biology, University of Joensuu, P.O. Box 111, FIN-80101 Joensuu, Finland

Received 3 May 1994, accepted 11 April 1996

\section{Introduction}

We have been searching for pattern in sawfly relationships to their host plants for the past 15 years, because the discovery of pattern in nature and its mechanistic explanation form the beginnings of factually based theory (Tilman 1989, Price 1991a). Although the generation of such theory forms the heart of a science, there has been inadequate concentration on generating theory in the fields of 
plant and herbivore interactions, and insect herbivore population dynamics. Even the strongly comparative study of several species in a genus, or several species with similar ecology, has not been well developed using field studies. This is in spite of the analytical power of comparative ecology in the detection of pattern and its underlying causes.

One of the problems the comparative ecologist faces is the choice of characters to compare, both in terms of plant heterogeneity to be measured, and the response of herbivores to this heterogeneity. Many approaches have been taken, from phytochemical characters to module age or size and geographical gradients (e.g. Denno \& McClure 1983, Bernays 1989-1994, Price et al. 1991a, Hunter et al. 1992). But broad general approaches, enabling broad comparisons among herbivores, have generally not been discovered.

One simple and general approach we have been advocating is to concentrate on the vigor, or ultimate size, of plant modules and plant age, as universally comparable attributes of plants and plant heterogeneity. Then the response of insect herbivores to such heterogeneity can be measured in terms of patterns of attack and survival, or their lack (Price 1991b, Price et al. 1995a). Such simple metrics of plants enable rapid collection of data and assessment of herbivore responses and a simple approach to the detection of pattern, and often the selective advantage of a pattern to the herbivore (e.g. Price et al. 1987ab, Price 1989, Roininen et al. 1993a, 1995, Price \& Roininen 1993).

One genus of sawflies, Euura Newman (Hymenoptera: Tenthredinidae), which has revealed strong and consistent pattern includes the stem, bud, petiole and midrib gallers known to attack only members of the plant family Salicaceae, in- cluding the willows, Salix, and poplars, Populus. Within this genus we have studied seven species, and have found a consistent pattern of oviposition preference on the longer shoot length classes available on a plant or among plants (Table 1). Coupled with this is generally higher survival of progeny on the preferred shoots, resulting in a strong preference-performance linkage in these sawflies (e.g. Craig et al. 1989, Price et al. 1995b). Thus we have a pattern detected for seven species, and an explanation for pattern based on the selective advantage for females ovipositing into rapidly growing shoots, which ultimately enter into the longer shoot length classes. In addition, for two Euura species we know the proximate chemical cues used by females as oviposition stimulants. Both are phenolic glucosides (Kolehmainen et al. 1994, Roininen et al. 1995). We know of no other research programs which have discovered such broad-based patterns, and their explanation, among related herbivore species in response to host plant heterogeneity.

It may appear to be redundant to report on further evidence for these patterns in yet another species of Euura. However, in the development of theory, the strength of the pattern and the weight of evidence supporting pattern is crucial. A new example provides a test of the predictive power of the developing hypotheses. In addition, this example provides data on only the third species to be studied in some detail on a willow tree species. All other examples come from sawflies attacking shrubby willows (Table 1).

As with the other sawfly species we have studied, we asked the following questions:

1. What is the pattern of attack by Euura females in relation to shoot length in a population of shoots on the willow host plant?

Table 1. Species of Euura and their host plants studied to date in which preference-performance linkage has been established.

\begin{tabular}{llllll}
\hline Euura species & Willow species & Plant form & Gall type Location & Reference \\
\hline E. amerinae L. & S. pentandra L. & Tree & Stem & Joensuu, Finland & Roininen et al. 1993a, 1995 \\
E. exiguae Smith & S. exigua Nuttall & Shrub & Stem & Weber River, Utah & Price 1989 \\
E. lasiolepis Smith & S. lasiolepis Bentham & Shrub & Stem & Flagstaff, Arizona & Craig et al. 1989 \\
E. mucronata (Hartig) & S. cinerea L. & Shrub & Bud & Joensuu, Finland & Price et al. 1987ab \\
E. "mucronata" & S. sachalinsis F. Schmidt & Tree & Bud & L. Shitose, Hokkaido, Japan P.W. Price \& T. Ohgushi, unpub. \\
E. s-nodus? Walsh & S. interior Rowlee & Shrub & Stem & Tanana River, Alaska & P.W. Price \& H. Roininen, unpub. \\
E. n. sp. & S. exigua Nutlall & Shrub & Midrib & Grand Canyon, Arizona & Woods et al. 1995 \\
\hline
\end{tabular}


2. What is the pattern of survival of eggs and larvae in galls in terms of establishment of a feeding site in the gall, and survival to a late instar larva or adult?

3. If patterns exist, what is the mechanistic explanation, involving either bottom-up plant effects, or top-down carnivore effects?

\section{Organisms studied}

We studied the species on $S$. alba $\mathbf{L}$. in Joensuu, Finland, in the spring of 1986 . Within the city, parkland and roadside trees of $S$. alba and $S$. fragilis L. grow as ornamentals, both introduced from natural populations which reach up to St. Petersburg and Lake Ladoga in Russia, near the boundary with Finland. The three sibling species discovered by Roininen et al. (1993b) have recently been named by Kopelke (1996). The sibling species status of the bud gallers in the E. mucronata (Hartig) complex remains unresolved, but we expect the two species in Table 1 to be diagnosed as separate species in the near future (cf. Price \& Roininen 1993, Price et al. 1995b).

E. atra is usually hard to find on willows in Finland, but is more abundant on S. alba and S. fragilis than its sibling species on the other hosts (Roininen et al. 1993b). This is probably a result of frequent pruning of these omamentals in the managed landscapes they are planted in (cf. Price \& Roininen 1993). Heavy pruning results in rapid growth of remaining shoots, and it is in such growth after damage that $E$. atra has been found in Joensuu.

In $S$. alba the sawfly forms a small usually inconspicuous gall in the current year's growth. It was even called a shoot borer rather than a galler by MacCall et al. (1972), but this observation failed to note the gall tissue within the stem. In the fall, the larva bores an exit hole, spins a cocoon in the shoot and overwinters. In the spring pupation occurs and adults emerge in late May and early June in the Joensuu area. The exit holes make the presence of galls more easily identified. In early June, 1986, we collected pruned branches from several roadside trees and opened the galls present to determine their contents.

\section{Methods}

The shoots examined in 1986 had grown in 1985 so they were fully grown, and some had been attacked in June 1985 while they were developing rapidly. The 151 shoots examined represented a haphazard sample of shoots available on the trees, and sawflies had attacked shoots in every tree, indicating that all shoots used in the sample were within the cruising range of the female sawfly population. A total of 81 galls were discovered on 151 shoots, which represented a large proportion of those available in the pruned material.
Shoots were measured for length whether they were attacked or not, and any galls found were opened. Gall content was recorded as a living larva, pupa, adult or parasitoid, and an empty cocoon signified an emerged adult. Dead larvae were recorded, and bird predation could be identified when the gall was pecked open. Therefore we were able to estimate the kind of shoot attacked by females, and the survival of their progeny. We could evaluate the existence of a preference-performance linkage. The number of larvae established in galls included all survivors, plus those parasitized and preyed upon. This provided an estimate of success based on the plant-herbivore interaction during the critical stage of the first instar larvae (cf. Preszler \& Price 1988). The per cent surviving included only survivors after larval death from unknown causes, parasitoid attack and predation, representing mainly the top-down impact of carnivores.

Shoots and any galls present were grouped into $50-\mathrm{mm}$ shoot length classes. The number of shoots, galls, established larvae, and survivors were counted per shoot length class and per cent established and survived were calculated. Simple linear regressions were used to test for significant patterns in the probability of attack, number of galls per 100 shoots, and per cent established and survived, all in relation to the independent variable shoot length class. At the higher shoot length categories shoot length classes were grouped to ensure at least five shoots per class. Chi ${ }^{2}$ tests indicated any differences between observed and expected attacks, if random, in relation to cumulative shoot length per class and number of shoots per class.

\section{Results}

\subsection{Willow growth}

The young pruned trees used as sample material had grown very vigorously in 1985 , with the most common shoot-length classes at $200-400 \mathrm{~mm}$ (Fig. 1). Even on shrubby willows such as $S$. cinerea and $S$. lasiolepis maximum shoot lengths were within this range, as well as in samples from the tree S. sachalensis (cf. Price et al. 1995b). However, maximum shoot lengths on $S$. alba reached close to $1 \mathrm{~m}$ long.

\subsection{Pattern of attack}

The probability of attack per shoot length class increased with increasing shoot length (Fig. 1, $Y=$ $\left.\left(1.30 \times 10^{-3}\right) X-0.17, r^{2}=0.91, n=11, p<0.01\right)$. Shoot length class accounted for $91 \%$ of the variance in attack, showing a strong effect on female ovipositional choice. As a result, the estimated 

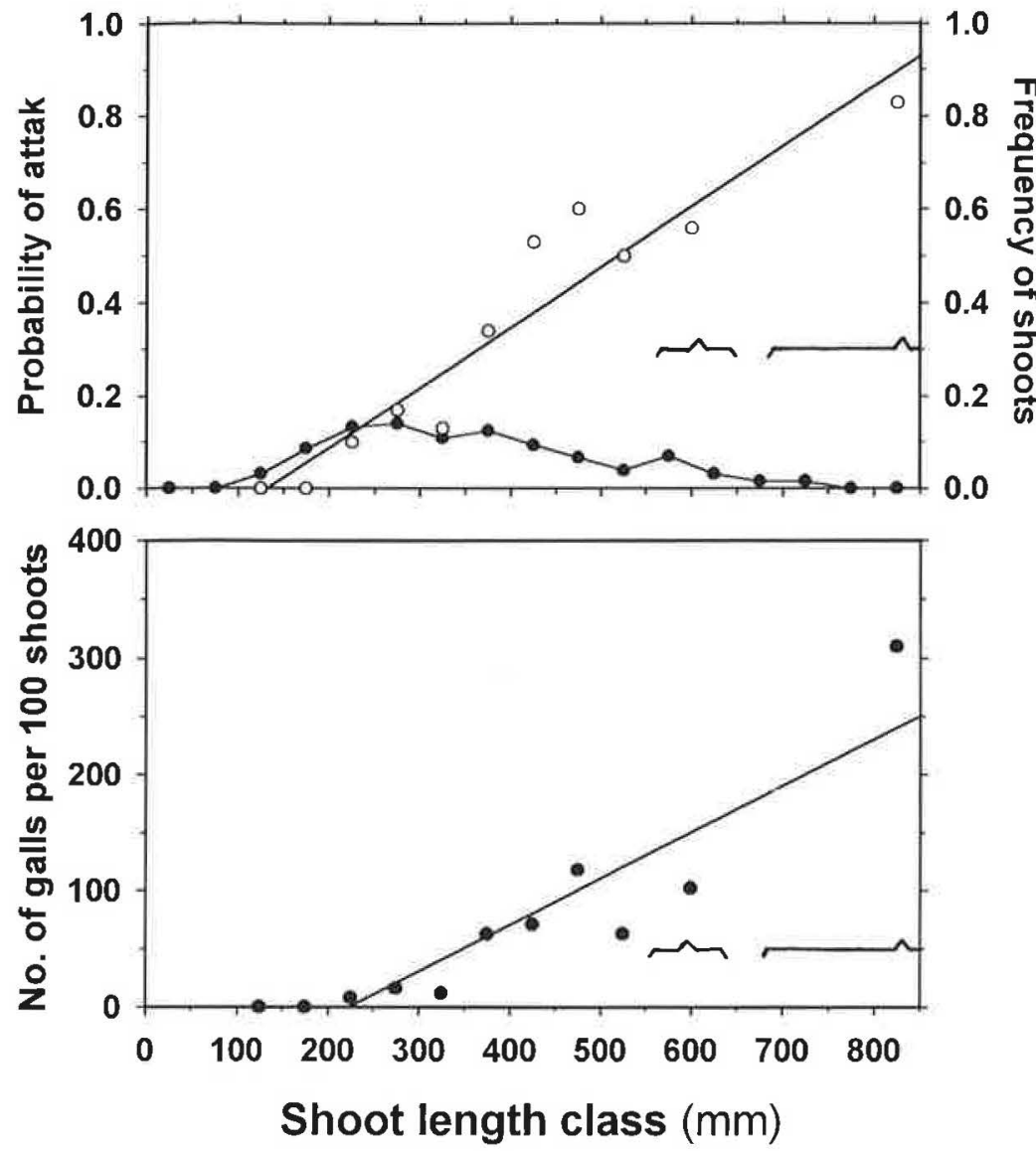

Fig. 1. The relationship between shoot length class and frequency of shoots per class (top, solid circles), and the probability of attack by Euura atra (top, open circles). The regression line accounts for $91 \%$ of the variance in the probability of attack. The number of galls per 100 shoots in relation to shoot length class (below). The regression line accounts for $83 \%$ of the variance in number of galls per 100 shoots. Upper shoot length classes were bracketed to ensure at least five shoots per class. number of galls per 100 shoots increased with shoot length class (Fig. 1, $Y=0.41 X-89.69, r^{2}=$ $0.83, n=11, p<0.01)$. The shortest shoot length categories were not attacked.

Note that the cumulative shoot length per class was much higher in the lower classes than in the highest classes, so random attack would have yielded more attacks in the lower classes than observed. For example, the 151-200-mm shoot length class was represented by 14 shoots with a cumulative length of $2450 \mathrm{~mm}$ but no attacks, while the longest shoots above $700 \mathrm{~mm}$ were all attacked even though in any 50 -mm class cumulative shoot length did not exceed $1450 \mathrm{~mm}$. Even more restrictive is the fact that females oviposit only at the growing tip of a shoot so number of shoots per class should give a good prediction of number of attacks if they are random. Clearly females are highly selective, showing a strong preference for the longer shoot length classes. When expected number of attacks per shoot length class, based on random attack, are estimated using total shoot length per class, and compared with actually observed attacks, the difference is highly significant, with many more attacks than observed on lower shoot length classes $\left(\chi^{2}=37.02, n=11\right.$, $p<0.005$ ). When a similar comparison is made using number of shoots per shoot length class, an equivalent result was found $\left(\chi^{2}=115.55, n=11\right.$, $p<0.005$ ).

\subsection{Pattern of establishment and survival}

The per cent of galls with larvae established increased with increase in shoot length class (Fig. 2, $\left.Y=2.50+0.14 X, r^{2}=0.70, n=13, p<0.01\right)$. The pattern in survival was similar (Fig. $2, Y=1.31+$ $\left.0.09 X, r^{2}=0.50, n=13, p<0.01\right)$. When shoots were over $350 \mathrm{~mm}$ long the establishment of lar- 
Fig. 2. The relationship between shoot length class and the per cent of larvae which established feeding sites in galls (open circles and solid regression line), and the per cent which survived until early June 1986 (closed circles and dashed regression line). The regressions accounted for $70 \%$ and $50 \%$ of the variance respectively. Upper shoot length classes were bracketed to ensure at least five shoots per class.

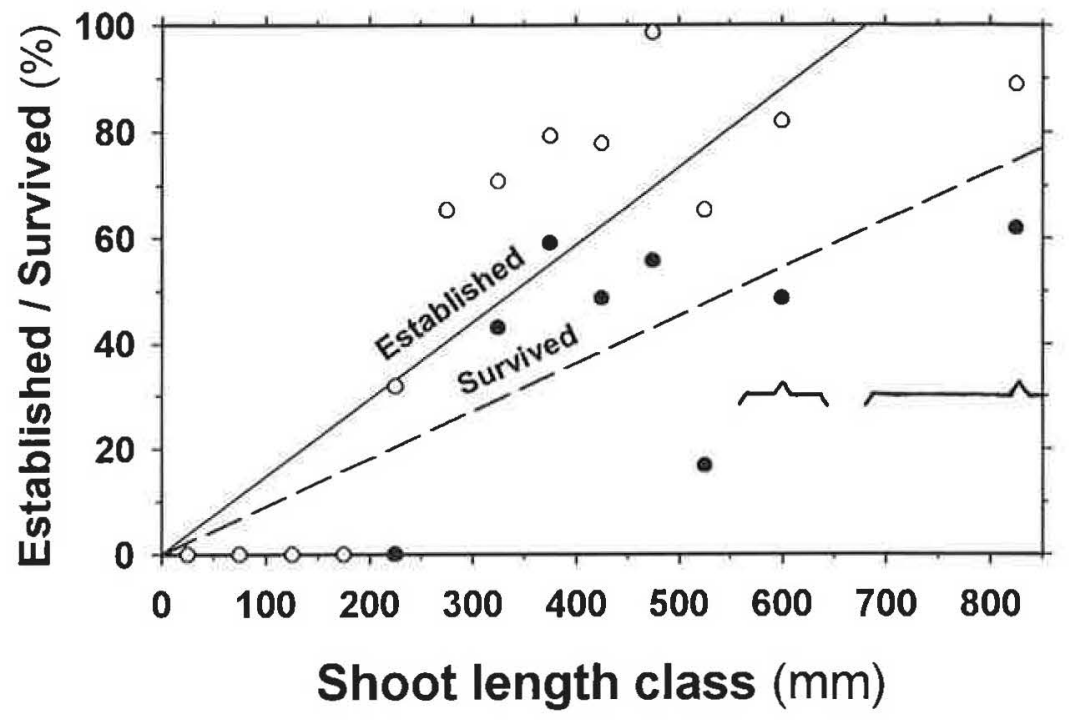

4. A strong preference-performance linkage was detected.

5. Carnivores had no detectable effects on the development of pattern in attack and survival.

6. Strong effects on pattern were generated from the bottom up through the host plant.

These conclusions provide clear answers to the questions raised in the introduction, and at the initiation of the study.

In our studies of Euura sawflies, it has usually proved to be most unusual to find populations high enough to enable a study, even with the relatively small number of galls used in the present research. The heavy and continued pruning of trees in managed landscapes clearly provided the kind of conditions in which $E$. atra became more abundant than under natural conditions. A similar case concerns E. amerinae, where human disturbance provides open ground for colonization by the host plant, S. pentandra L., followed by an only brief residence time of the sawfly on young trees (Roininen et al. 1993a, 1995). It would be valuable to study $E$. atra in more natural conditions in relation to the demography of its native hosts, and to compare the impact of tree age on sawfly population dynamics with dynamics of $E$. amerinae.

An interesting aspect of Euura host plant utilization is that trees have been colonized only rarely. No trees in the genus Populus are known to support a Euura species population consistently, 
and E. atra and E. amerinae are two of the very few species known to attack Salix trees. We have hypothesized that trees become resistant to Euura attack rapidly as they age, because young juvenile shoots are not continually produced from the root stock, as in shrubs (Price \& Roininen 1993). Thus, all parts of the tree are subject to ontogenetic and physiological aging, and an individual plant becomes resistant to species like Euura that colonize juvenile growth (cf. Kearsley \& Whitham 1989). As a consequence, young, rapidly growing populations of host trees, available only for a few years, become a very limiting resource over a landscape, reducing the probability of a host shift from a shrub to a tree species. We have followed the local colonization and extinction of an $E$. amerinae population to test the hypothesis (Roininen et al. 1993a). All results were consistent with the hypothesis although the nature of the resistance factor is still a mystery. The results on E. atra, found attacking heavily pruned, young, and rapidly growing trees in a managed landscape, are also consistent with the hypothesis. However, dynamics in natural populations of hosts are needed for stronger tests of the tree aging hypothesis.

We are convinced that such broadly comparative studies on genera like Euura, and among related genera, are essential for the development of empirically based general theory. Based on our research on Euura we have claimed that such general theory can be developed (Price et al. 1995a), although predictions from the theory need continual testing, as in the present study. From the rather narrow perspective of one genus, we are expanding to other galling and free-feeding sawflies, to test the extent to which patterns and mechanisms relevant to Euura can be observed in related sawflies. We have even argued that the study of these relatively uncommon and rare herbivore species shed light on why other species become pests with eruptive population dynamics (Price et al. 1991). Hence, it may be possible to expand theory from the narrow perspective of a single genus to a broad understanding of insect herbivore population dynamics. We feel that this study on E. atra is but one step in a strongly comparative approach which gradually builds toward as broad a theory as the evidence allows.
Acknowledgments: P.W.P.'s research was supported by N.S.F. grants BSR-83144594, BSR-8705302, BSR8715090 , BSR-9020317 and DEB-9318188. H.R. and J.T. were supported by the Finnish Academy.

\section{References}

Bernays, E. A. (ed.) 1989, 1990, 1991, 1992, 1994: Insectplant interactions. Vols. 1, 2, 3, 4, 5. - CRC Press, Boca Raton, Florida.

Craig, T. P., Itami, J. K. \& Price, P. W. 1989: A strong relationship between oviposition preference and Jarval performance in a shoot-galling sawfly. — Ecology 70: 1691-1699.

Denno, R. F. \& McClure, M. S. (eds.) 1983: Variable plants and herbivores in natural and managed systems. Academic Press, New York.

Hunter, M. D., Ohgushi, T. \& Price, P. W. (eds.) 1992: Effects of resource distribution on animal-plant interactions. - Academic Press, San Diego.

Kearsley, M. J. C. \& Whitham. T. G. 1989: Developmental changes in resistance to herbivory: Implications for individuals and populations. - Ecology 70: 422-434.

Kolehmainen, J., Roininen, H., Julkunen-Tiitto, R. \& Tahvanainen, J. 1994: Importance of phenolic glucosides in host selection of the shoot-galling sawfly, Euura amerinae, on Salix pentandra. — J. Chem. Ecol. 20: 24552466.

Kopelke, J.-P. 1996: Die Euura atra- und amerinae-Gruppe in Nord- und Mitteleuropa. - Senckenbergiana Biologia 76: 93-113.

MacCall, C. D.,Titus, F. A. \& Rose, A. H. 1972: A willow shoot-boring sawfly Euura atra (Jurine). - Can. Dept. Environ. For. Serv. Bi-Mon. Res. Notes 28: 8.

Preszler, R. W. \& Price, P. W. 1988: Host quality and sawfly populations: A new approach to life table analysis. Ecology 69: 2012-2020.

Price, P. W. 1989: Clonal development of coyote willow, Salix exigua (Salicaceae), and attack by the shoot-galling sawfly, Euura exiguae (Hymenoptera: Tenthredinidae). - Environ. Entomol. 18: 61-68.

Price, P. W. 1991a: Darwinian methodology and the theory of insect herbivore population dynamics. - Ann. Entomol. Soc. Amer. 84: 465-473.

Price, P. W. 1991b: The plant vigor hypothesis and herbivore attack. — Oikos 62: 244-251.

Price, P. W. \& Roininen, H. 1993: The adaptive radiation of gall induction. - In: Wagner, M. R. \& Raffa, K. F. (eds.), Sawfly life history adaptations to woody plants: 229-257. Academic Press, San Diego.

Price, P. W., Roininen, H. \& Tahvanainen, J. 1987a: Plant age and attack by the bud galler, Euura mucronata. Oecologia (Berl.) 73: 334-337.

Price, P. W., Roininen, H. \& Tahvanainen, J. 1987b: Why 
does the bud-galling sawfly, Euura mucronata, attack long shoots? - Oecologia (Berl.) 74: 1-6.

Price, P. W., Cobb, N., Craig, T. P., Fernandes, G. W., Itami, J. K., Mopper, S. \& Preszler, R. W. 1991a: Insect herbivore population dynamics on trees and shrubs: New approaches relevant to latent and eruptive species and life table development. - In: Bernays, E. A. (ed.), Insect-plant relationships: $1-38$. CRC Press, Boca Raton, Florida.

Price, P. W., Lewinsohn, T. M., Fernandes, G. W. \& Benson, W. W. (eds.) 1991b: Plant-animal interactions: Evolutionary ecology in tropical and temperate regions. John Wiley, New York.

Price, P. W., Andrade, I., Pirez, C., Sujii, E. \& Vieira, M. E. 1995a@: Gradient analysis using plant modular structure: Pattern in plant architecture and insect herbivore utilization. - Environ. Entomol. (In press.)

Price, P. W., Craig, T. P. \& Roininen, H. 1995b: Working toward theory on galling sawfly population dynamics. - In: Cappuccino, N. \& Price, P. W. (eds.), Population dynamics: New approaches and synthesis: $321-$
338. Academic Press, San Diego.

Roininen, H., Price, P. W. \& Tahvanainen, J. 1993a: Colonization and extinction in a population of the shootgalling sawfly, Euura amerinae. - Oikos 68: 448-454.

Roininen, H., Vuorinen, J., Tahvanainen, J. \& JulkunenTiitto, R. 1993b: Host preference and allozyme differentiation in a shoot-galling sawfly, Euura atra. - Evolution 47: 300-308.

Roininen, H., Price, P. W. \& Tahvanainen, J. 1995: Bottom-up and top-down influences in the trophic system of a willow, a galling sawfly, parasitoids and inquilines. - Oikos 77: 44-50.

Tilman, D. 1989: Discussion: Population dynamics and species interactions. - In: Roughgarden, J., May, R. M. \& Levin, S. A. (eds.), Perspectives in ecological theory: 89-100. Princeton University Press, Princeton, New Jersey.

Woods, J. O., Carr, T. G., Price, P. W., Stevens, L. \& Cobb, N. S. 1996: Growth of coyote willow and the attack and survival of a midrib galling sawfly, Euura sp. Oecologia 108: 714-722. 